\title{
EDUKASI TATA LAKSANA NON FARMAKOLOGI UNTUK PENCAPAIAN TEKANAN DARAH TERKONTROL PADA PENYANDANG HIPERTENSI DI POSBINDU PTM DESA DUKUHWALUH KEMBARAN
}

\author{
Tri Sumarni ${ }^{1}$, Reni Dwi Setyaningsih ${ }^{2 *}$ \\ ${ }^{1}$ Program Studi Keperawatan D3, Fakultas Kesehatan, Universitas Harapan Bangsa, Purwokerto, Indonesia \\ ${ }^{2}$ Program Studi Keperawatan S1, Fakultas Kesehatan, Universitas Harapan Bangsa, Purwokerto, Indonesia \\ *Penulis Korespodensi : reni.dws@gmail.com
}

\begin{abstract}
Abstrak
Hipertensi merupakan salah satu penyakit tidak menular yang menjadi masalah utama kesehatan masyarakat. Prevalensinya yang cenderung meningkat serta potensi risiko komplikasi yang mengancam menyebabkan dibutuhkan upaya yang sistematis dalam rangka pengendalian penyakit melalui program Posbindu PTM. Manajemen terapi hipertensi harus dilakukan seumur hidup, baik terapi farmakologi maupun non farmakologi, untuk dapat menurunkan munculnya risiko komplikasi dan meningkatkan kualitas hidup penyandang. Hal ini menyebabkan perlunya pendampingan melalui pemberian edukasi bagi penyandang hipertensi dalam rangka pencapaian tekanan darah terkontrol dan pengurngan gejala Hipertensi sehingga risiko komplikasi dapat ditekan. Posbindu Desa Dukuh waluh masih didapatkan beberapa peserta yang tidak rutin datang, dan tidak mengetahui pentingnya pengontrolan gaya hidup sebagai bagian dari terapi non farmakologi. Pemberian edukasi tentang hipertensi dan tata laksanan non farmakologik dilakukan dengan metode pendidikan kelompok melalui ceramah dan diskusi dengan sasaran peserta posbindu yang teridentifikasi sebagai penyandang hipertensi, yaitu sebanyak 25 peserta. Hasil akhir kegiatan didapatkan adanya peningkatan rerata skor pengetahuan sasaran sebesar 2.6 point dan penurunan tekanan darah sistolik dan diastolik masing-masing sebesar 15.6 dan 7.6 point. Pemberian edukasi penting bagi penyandang hipertensi untuk dapat mematuhi manajemen terapi farmakologik dan non farmakologik.
\end{abstract}

Kata kunci: Hipertensi, posbindu, edukasi, non farmakologi

\begin{abstract}
Hypertension is one of the non-communicable diseases (PTM) which is a major problem for public health. The prevalence that tends to increase and the potential risk of threatening complications causes systematic efforts to control disease through the Integrated Development Post (Posbindu) program. Management of therapy for hypertension must be carried out for life, both pharmacological and nonpharmacological therapies, to reduce the risk of complications and to improve the quality of life for people. This causes the need for assistance through the provision of education for people with hypertension in order to achieve controlled blood pressure and reduce symptoms of hypertension so that the risk of complications can be reduced. In Posbindu Dukuhwaluh, there are still some participants who do not routinely come, and do not know the importance of controlling lifestyle as part of nonpharmacological therapy. Providing education about hypertension and non-pharmacological procedures was carried out by the method group discussion with the aim of 25 Posbindu participants identified as having hypertension. The final result of the activity found an increase in the mean target knowledge score of 2.6 points and a decrease in systolic and diastolic blood pressure of 15.6 and 7.6 points respectively. Providing education is important for people with hypertension to be able to adhere to the management of pharmacological and non-pharmacological therapies.
\end{abstract}

Keywords: Hypertension, posbindu, education, non-pharmacological

\section{PENDAHULUAN}

Hipertensi ynag didefiniskan sebagai tekanan darah sistolik lebih dari $140 \mathrm{mmHg}$ atau tekanan diastolik lebih dari 90 mmHg merupakan tantangan kesehatan masyarakat yang utama di seluruh dunia. Pencegahan, deteksi, pengobatan, dan pengendalian hipertensi harus mendapatkan prioritas yang utama (Burnier \& Egan, 2019). Hipertensi juga bertanggung jawab terhadap $45 \%$ kematian akibat penyakit jantung dan $51 \%$ kematian akibat stroke (WHO, 2013). Pevalensi ini 
semakin meningkat seiring dengan pertambahan umur (Profil Kesehatan Indonesia, 2017). Kasus hipertensi untuk wilayah Banyumas tahun 2017 yaitu sebanyak 55,79\% (DKK Banyumas, 2018). Secara epidemiologi, hipertensi di masyarakat lebih banyak disebabkan oleh dua faktor besar yaitu peningkatan usia dan meningkatnya prevalensi obesitas. Hipertensi juga dihasilkan dari faktor genetik (keturunan) dan gaya hidup seperti obesitas, diet tinggi natrium, paparan stress persisten, konsumsi alkohol berlebihan dan kurang aktivitas fisik (Rusdi, 2009).

Hipertensi seringkali disebut sebagai the silent killer. Proses penyakit ini sangat perlahan dan bahkan hipertensi bisa tidak menunjukkan gejala sampai terjadinya kerusakan organ seperti stroke atau serangan jantung (Kemenkes RI, 2014). Tanda dan gejala hipertensi awal yang menyerupai gejala penyakit lain diantaranya adalah nyeri kepala, berat dan kaku di tengkuk, dada berdebar-debar, gelisah, pandangan kabur dan mudah lelah (Prince, 2012). Hipertensi yang tidak terkontrol dapat memicu timbulnya komplikasi kardiovaskuler. Stroke, penyakit jantung, penyakit ginjal dan kebutaan merupakan komplikasi kardiovaskuler tersering dan risiko mengalaminya semakin tinggi seiring dengan tingginya tekanan darah (James, 2014). Berdasarkan hasil penelitian, angka kematian di dunia akibat komplikasi hipertensi mencapai 9,4 juta setiap tahunnya (WHO, 2013).

Angka morbiditas dan mortalitas akibat hipertensi dapat diminimalisir dengan penatalaksanaan farmakologi dan non farmakologi. Penatalaksanaan farmakologi dilakukan dengan pemberian obat antihipertensi. Penatalaksanaan non farmakologi dapat dilakukan melalui modifikasi gaya hidup, seperti diet Dietary Approaches to Stop Hipertension (DASH), mengurangi asupan natrium, menurunkan berat bedan, olahraga secara teratur, tidak konsumsi alkohol, dan tidak merokok (Hedayati, 2011). Pengobatan non farmakologi sama pentingnya dengan pengobatan farmakologi. Pengobatan farmakologi dapat memberikan efek samping, sehingga penderita hipertensi dianjurkan terapi dengan menggunakan pendekatan non farmakologi untuk menurunkan tekanan darah (Gofir, 2012).

Pendidikan kesehatan bagi penyandang Hipertensi dapat berdampak terhadap meningkatkan kesadaran pasien agar tekanan darah terkontrol dan terjadi penurunan gejala. Upaya kesehatan tersebut terfokus pada upaya peningkatan perilaku sehat, mendorong perilaku yang menunjang kesehatan, pencegahan penyakit, pengobatan dan pemulihan penyakit (Notoatmodjo, 2012).

Salah satu bentuk Upaya Kesehatan Berbasis Masyarakat (UKBM) yang dikembangkan oleh Pemerintah sesuai dengan rekomendasi WHO adalah Posbindu PTM (Kemenkes RI, 2012). Berdasarkan hasil wawancara dengan kader Posbindu PTM di Desa Dukuh Waluh, didapatkan informasi bahwa ada beberapa peserta yang memiliki tekanan darah yang tinggi yang kurang dilakukan perawatan secara berkala sehingga tekanan darah menjadi tidak terkontrol. Aktivitas fisik seperti senam rutin tetapi juga tidak dimanfaatkan secara maksimal. Sebagian besar peserta juga tidak berpantang terhadap makanan tinggi kolesterol dan tinggi garam yang berpotensi makin meningkatnya tekanana darah. Hal ini disebabkan karena peserta belum mengetahui tentang terapi non farmakologi untuk menurunkan tekanan darah dan gejala hipertensi dan belum pernah diberikan edukasi kepada peserta tentang pentingnya manajemen terapi hipertensi secara non farmakologi.

Apabila penderita hipertensi mengetahui tentng terapi non farmakologi untuk menurunkan tekanan darah, maka kecacatan dan kematian akibat dari penyakit hipertensi dapat diminimalkan. Sehubungan dengan hal tersebut perlu dilakukan edukasi tentang tata laksana non faramakologi untuk menurunkan tekanan darah dan gejala hipertensi agar tekanan darah penderita hipertensi dapat terkontrol sehingga kesakitan dan kematian akibat hipertensi dapat dicegah.

Posbindu PTM Desa Dukuhwaluh merupakan Pos Pembinaan Terpadu Penyakit Tidak Menular yang ada di Desa Dukuhwaluh yang pelayanannya digabung dengan posyandu lansia. Peserta rutin sebanyak 60 orang, dengan lebih dari sepertiganya adalah penyandang Hipertensi (38\%) denagn separuhnya memiliki indeks massa tubuh $\geq 25$. Hampir sebagian besar peserta mengatakan bahwa Hipertensi hanya cukup diobati dengan konsumsi obat saja tanpa perlu diimbangi dengan gaya hidup sehat seperti, manajemen diet rendah garam, pola istirahat, stress serta aktivitas fisik. Hasil wawancara petugas / kader Posbindu juga didapatkan bahwa belum pernah diberikan edukasi khusus terkait penatalaksanaan non farmakologi bagi penyandang Hipertensi. Aktivitas pelayanan Posbindu lebih banyak kepada pemeriksaan kesehatan dasar seperti pengukuran berat badan dan tinggi badan serta tekanan darah. Informasi lain menyebutkan bahwa ada beberapa peserta Posbindu yang mengalami riwayat tekanan darah yang tinggi yang kurang dilakukan perawatan secara berkala sehingga tekanan darah menjadi tidak terkontrol, termasuk tidak aktif mengikuti kegiatan yang diadakan di Posbindu seperti senam rutin dan masih mengkonsumsi makananmakanan yang memperburuk kondisi Hipertensi atau dalam hal ini tidak mempraktekkan gaya hidup sehat.

Kebutuhan edukasi tentang penatalaksanaan Hipertensi secara non farmakologik menjadi hal penting bagi peserta Posbindu. Hal ini sesuai dengan prinsip penanganan Hipertensi yaitu perlunya kombinasi terapi farmakologi dan non farmakologi terutama bagi penyandang Hipertensi diatas grade 1. Terapi non farmakologi untuk penanganan hipertensi berupa anjuran modifikasi gaya hidup. Pola hidup sehat dapat menurunkan darah tinggi (Whelton, 1998; Whelton, 2015). 
Berkaitan dengan hal tersebut perlu diberikan edukasi tentang penatalaksanaan non farmakologi bagi penyandang Hipertensi di Posbindu PTM Desa Dukuhwaluh. Diharapkan dengan pemberian edukasi ini selain dapat meningkatkan pengetahuan penyandang Hipertensi juga dapat mencegah komplikasi dan menurunkan morbiditas yang pada akhirnya dapat meningkatkan kualitas hidup penyandang.

\section{BAHAN DAN METODE}

Program pengabdian masyarakat ini dilaksanakan di Posbindu PTM Desa Dukuhwaluh dengan sasaran 25 peserta. Metode pelaksanaan kegiatan pengabdian masyarakat ini meliputi beberapa tahapan yaitu : Persiapan dan koordinasi, pemberian edukasi pada khalayak sasaran, dan evlauasi. Pada tahap persiapan dan koordinasi dilakukan dengan metode survey lapangan, pengurusan perijinan dan anjangsana dengan tokoh masyarakat dan kader kesehatan desa. Pengurusan perijinan dilakukan melalui beberapa instansi terkait sesuai peraturan di wilayah Kabupaten Banyumas. Koordinasi pelaksanaan teknis bertujuan untuk memberikan gambaran pelaksanaan kegiatan, mendapatkan dukungan dan support serta membantu untuk mengidentifikasi kemungkinan faktor kendala dan faktor pendukung untuk mengatasi faktor kendala yang mungkin muncul.

Berikut ini langkah-langkah yang dilakukan dalam penerapan iptek bagi masyarakat Di Posbindu Desa Dukuh Waluh Kecamatan Kembaran" :

a. Screening Tekanan darah dan gejala hipertensi pada peserta Posbindu. Hal ini dilakukan dengan cara mengecek daftar kunjungan Posbindu dan memastikan peserta Posbindu yang memiliki tekanan darah konsisten tinggi serta melakukan pengukuran tekanan darah pada peserta Posbindu. Hasil Screening didapatkan 25 peserta teridentifikasi menyandang Hipertensi. Batasan Hipertensi ini adalah tekanan darah yang menetap tinggi dalam tiga kali pengukuran.

b. Edukasi tentang hipertensi dan tatalaksana non farmakologi hipertensi. Kegiatan edukasi diberikan sebanyak dua sesi diawali dengan pre tes tentang hipertensi dan tatalaksana non farmakologi hipertensi pada peserta Posbindu. Selanjutnya dilakukan pendidikan kesehatan dengan metode pendidikan kelompok, melalui ceramah dan diskusi.

c. Evaluasi dilakukan berkaitan dengan dampak dan hasil akhir dari kegiatan pengabdian masyarakat. Hal yang dievaluasi adalah peningkatan pengetahuan peserta posbindu tentang Hipertensi dan tata laksana non farmakologi serta tekanan darah dan pengurangan gejala Hipertensi pada pengukuran bulan berikutnya. Evaluasi dilakukan melalui wawancara dan pengukuran tekanan darah.

Secara lengkap alur pelaksanaan ditunjukkan pada gambar berikut :

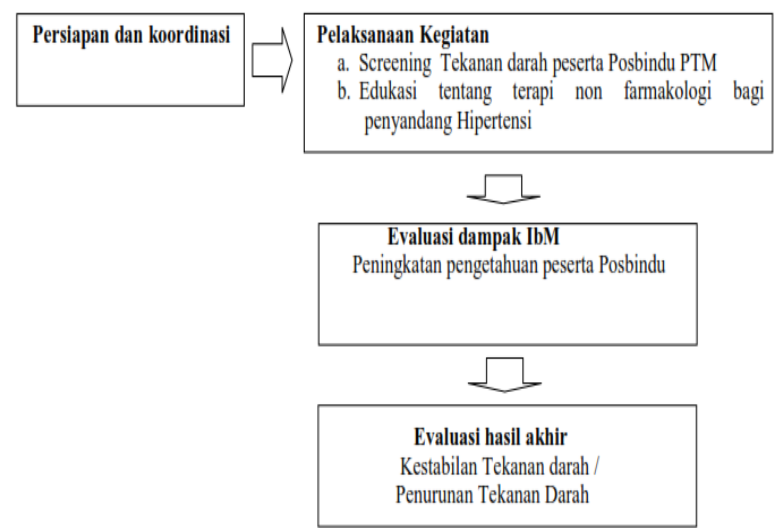

Gambar 1. Bagan Alur Pelaksanaan Ipteks bagi Masyarakat.

\section{HASIL DAN PEMBAHASAN}

Pemberian edukasi kepada peserta Posbindu PTM didapatkan bahwa pengetahuan peserta Posbindu PTM tentang hipertensi dan tata laksana terapi non farmakologi mengalami peningkatan skor pengetahuan rata-rata sebesar 2.6 point dan tekanan darah sistolik dan diastolik juga megalami penurunan masing-masing sebesar 15.2 dan 7.6 point (Tabel 1).

Beragam studi menunjukkan bahwa tingkat pengetahuan yang baik tentang hipertensi akan berdampak postif terhadap kontrol tekanan darah pada penyandang hipertensi (Samal dkk, 2007). Paparan informasi secara terus menerus dan berulang yang diberikan pada kegiatan Posbindu PTM akan secara bertahap meningkatan pengetahuan serta kesadaran penyandang hipertensi peserta posbindu PTM untuk mempraktekkan gaya hidup sehat sebagai bagian terapi non farmakologi tanpa mengesampingkan terapi farmakologi. Peningkatan pengetahuan yang diiringi dengan peningkatan kesadaran yang baik tentang hipertensi dan penatalaksanaannya secara non farmakologik ini juga dibuktikan dengan adanya penurunan tekanan darah baik sistolik maupun diastolik, dengan rerata penurunan tekanan darah sistolik dan diastolik masing-masing sebesar 15.2 dan $7.6 \mathrm{mmHg}$ (Tabel 1)

Tabel 1

Skor Pengetahuan, Tekanan Darah dan Keberadaan Gejala Hipertensi Peserta Posbindu Sebelum dan Sesudah Diberikan Edukasi tentang Hipertensi dan Tata Laksana Terapi Non Farmakologi

\begin{tabular}{llcc}
\hline \multicolumn{1}{c}{ Indikator } & Parameter & Mean & Selisih \\
& & & \\
\hline Skor Pengetahuan & Sebelum & 12.4 & 2.6 \\
& Sesudah & 15.0 & \\
Tekanan Darah Sistolik & Sebelum & 154.4 & 15.2 \\
& Sesudah & 139.2 & \\
Tekanan Darah Diastolik & Sebelum & 92.8 & 7.6 \\
& Sesudah & 85.2 & \\
\hline
\end{tabular}

Hasil resume wawancara dengan kader / petugas Posbindu PTM serta penyandang Hipertensi setelah diberikan edukasi tentang Hipertensi dan penatalaksanaan non farmakologi mengatakan bahwa, edukasi ini penting sebagai pengingat tentang 
modifikasi gaya hidup sehat : pengaturan diit, aktivitas fisik, pola istirahat dan pengendalian stress; menjadi awal bagi perubahan perilaku yang positif yang dapat mengendalikan tekanan darah tidak menjadi tinggi terus-menerus.

Tekanan darah merupakan kondisi yang tidak stabil dikarenakan ada banyak hal yang mempengaruhinya. Penurunan tekanan darah yang diharapkan pasca pemberian edukasi pada penyandang hipertensi peserta posbindu PTM ini adalah tekanan darah yang terkendali, artinya stabil tidak terjadi peningkatan nilai baik pada sitolik maupun dastolik. Penurunan tekanan darah baik sistolik mauun diastoik pada penyandang hipertensi di Posbindu PTM ini merupakan dampak yang diharapkan, akan tetapi seandainya terjadi penurunan pun tidak secara ekstrim karena hal ini akan berdampak buruk bagi penyandang.

Pilihan non farmakologi terapi, termasuk didalamnya adopsi gaya hidup sehat merupakan bagian yang tidak terpisahkan dari manajemen pada pasien dengan hipertensi. Penurunan berat badan terbukti menurunkan tekanan darah dengan penurunan tekanan darah sistolik lima sampai $20-\mathrm{mm} \mathrm{Hg}$ per $10-\mathrm{kg}$ penurunan berat badan, demikian halnya pengurangan asupan natrium (2 menjadi $8 \mathrm{~mm} \mathrm{Hg}$ ) 19-21 dan aktivitas fisik reguler (4 hingga 9 mm Hg) (Kelley \& Kelley, 2000; Whelton dkk, 2002). Gejala hipertensi juga merupakan warning signal pada penyandang hipertensi.

Mayoritas orang dengan tekanan darah tinggi tidak memiliki tanda atau gejala, bahkan jika pembacaan tekanan darah sudah mencapai tingkat yang sangat berbahaya. Beberapa orang dengan tekanan darah tinggi mungkin mengalami sakit kepala, sesak napas atau mimisan, tetapi tanda dan gejala ini tidak spesifik dan biasanya tidak terjadi sampai tekanan darah tinggi telah mencapai tahap yang parah atau mengancam jiwa penyandang. Edukasi / konseling pada peserta Posindu PTM merupakan satu kesatuan disamping pemeriksaan kesehatan dan deteksi dini serta pemantauan faktor risiko yang tujuan akhirnya adalah adanya perubahan pengetahuan yang diikuti dengan perubahan sikap serta perubahan perilaku yang bersifat menetap pada sesorang.

Menurut Notoatmodjo bahwa pendidikan kesehatan, dalam hal ini bagi penyandang Hipertensi, dapat berdampak terhadap peningkatkan kesadaran pasien agar tekanan darah terkontrol. Upaya kesehatan tersebut terfokus pada upaya peningkatan perilaku sehat, mendorong perilaku yang menunjang kesehatan, pencegahan penyakit, pengobatan dan pemulihan penyakit (Notoatmodjo, 2012). Pemberian Edukasi ini diharapkan akan berkontribusi dalam penurunan morbiditas dan pencegahan komplikasi pada penyandang hipertensi. Hal ini sesuai dengan tujuan awal pembentukan Posbindu PTM, bahwa Posbindu PTM sebagai bagian integral dari pelayanan kesehatan dengan pelayanan promotif dan preventif yang dilakukan secara berkesinambungan dengan melibatkan peran serta masyarakat, sehingga kejadian penyakit tidak menular di masyarakat dapat ditekan (Kemenkes RI, 2012).

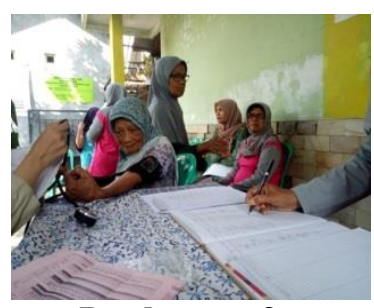

Pendataan \&

Pemeriksaan Tekanan Darah Peserta Posbindu PTM

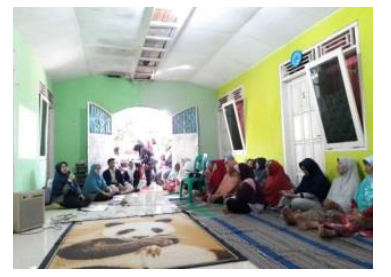

Paparan Materi / Penyuluhan Kesehatan

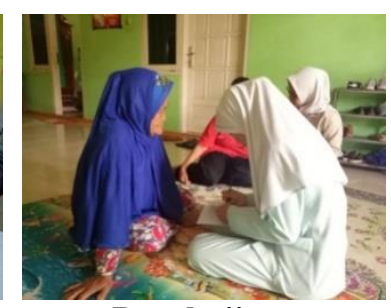

Pengkajian

Pengetahuan Awal Identifikasi Gejala Hipertensi pada Peserta Posbindu PTM

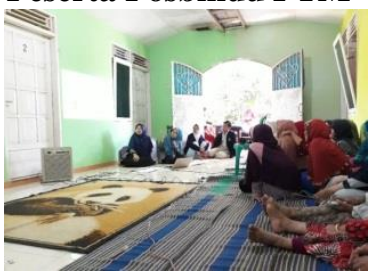

Paparan Materi /

Penyuluhan Kesehatan
Gambar 2. Dokumentasi Pelaksanaan Kegiatan di Posbindu PTM Desa Dukuhwaluh

\section{KESIMPULAN}

Hasil Akhir dari pemberian edukasi tata laksana non faramakologi bagi peserta Posbindu PTM tentang hipertensi dan tata laksana terapi non farmakologi yang dilaksanakan secara terprogram pada dua kali sesi pertemuan Posbindu PTM mengalami peningkatan skor pengetahuan rata-rata sebesar 2.6 point. Tekanan darah sistolik dan diastolik juga mengalami penurunan masing-masing sebesar 15.2 dan 7.6 point. Peserta kegiatan mengatakan bahwa pengetahuan tentang tata laksana non farmakologik sangat bermanfaat dan sebagai pintu masuk perubahan perilaku dalam mengontrol dan mengendalikan tekanan darah penyandang.

Hasil tersebut menunjukkan bahwa peran posbindu PTM penting sebagai upaya untuk menurunkan morbiditas hipertensi dengan menggabungkan pemeriksaan rutin tekanan darah, pemberian obat hipertensi serta edukasi sehingga risiko komplikasi dapat diturunkan serta meningkatkan kualitas hidup penyandang, dengan melibatkan peran aktif kader / petugas Posbindu PTM untuk meningkatkan aktivitas kunjungan peserta Posbindu PTM serta meningkatkan peran Puskesmas dengan memberikan pendampingan dan konseling terhadap penyandang dalam pelaksanaan Posbindu PTM.

\section{UCAPAN TERIMA KASIH}

Terima kasih disampaikan kepada Lembaga Penelitian dan Pengabdian Masyarakat Universitas Harapan Bangsa Purwokerto sesuai dengan Surat Perjanjian Penugasan Pelaksanaan Program Pengabdian 
Masyarakat Nomor: UHB/KEP/075/041, tanggal 15 April 2019 dan seluruh kader dan peserta Posbindu Desa Dukuhwaluh, Kecamatan Kembaran dan segenap pemerintahan Desa Dukuhwaluh sehingga kegiatan ini dapat terlaksana dengan baik.

\section{DAFTAR PUSTAKA}

Burnier, M., \& Egan, B. M. (2019). Adherence in Hypertension. Circulation Research, 124(7), 1124 1140.https://doi.org/10.1161/CIRCRESAHA.1 18.313220

Dinas Kesehatan Kabupaten Banyumas. (2018). Kasus penyakit tidak menular di puskesmas dan rumah sakit kabupaten / Kota Banyumas. Purwokerto

Gofir. (2012). Diagnosis \& Terapi Kedokteran. Jakarta: Salemba Medika

Hedayati, SS. (2011). Non-pharmacological aspects of blood management; what are the data?.Kidney International: 79: 1061-1070

James, PA. (2014) Report From The Panel Members Appointed To The Eighth Joint Based Guideline For The Management Of High Blood Pressure In Adults. JAMA : 311(5): 507520

Kementerian Kesehatan RI. (2014). Hipertensi. Jakarta: Pusat Data Informasi Kesehatan

Kementerian Kesehatan RI. (2012). Petunjuk Teknis Pos Pembinaan Terpadu Penyakit Tidak Menular (Posbindu PTM). Direktorat Jenderal Pengendalian Penyakit dan Penyehatan Lingkungan Direktorat Pengendalian Penyakit Tidak Menular.

Kelley GA., Kelley KS. (2000). Progressive resistance exercise and resting blood pressure: a metaanalysis of randomized controlled trials. Hypertension ; Vol 35: 838 - 843

Notoatmodjo, 2012. Promosi Kesehatan \& Ilmu Perilaku. Jakarta: Rineka Cipta

Prince. 2012. Pathophysiology Clinical Concepts of Disease Processes. Philadelphia: Mosby Year Book

Rusdi. (2009). Awas, Bisa Mati Cepat akibat Hipertensi dan Diabetes. Jogjakarta: IHDINA

Samal, D., Greisenegger, S., Auff, E., Lang, W., \& Lalouschek, W. (2007). The relation between knowledge about hypertension and education in hospitalized patients with stroke in Vienna. Stroke.

https://doi.org/10.1161/01.STR.0000259733.43 470.27

Whelton S.P., Chin A., Xin X., He J. (2002). Effect of aerobic exercise on blood pressure: a metaanalysis of randomized controlled trials. Ann Intern Med : 38:1112-1117

Whelton P.K., Appel L.J., Espeland M.A., et al., (1998). Sodium reduction and weight lossin the treatment of hypertension in older persons: a randomized controlled trial ofnonpharmacologic interventions in the elderly (TONE). TONE Collaborative Research Group. JAMA . Vol 279: 839-46.
Whelton P.K. (2015). The elusiveness of populationwide high blood pressure control. Annu Rev Public Health. Vol 36:109-30.

WHO. (2013). Implementation tools package of esential noncommunicable (PEN) disease intervention for primary health care in low resources settings. Geneva : WHO 